\title{
An Equity Analysis on the Household Costs of Accessing and Utilising Primary Health Care Services in Tanzania
}

Peter Binyaruka ( $\nabla$ pbinyaruka@ihi.or.tz)

Ifakara Health Institute https://orcid.org/0000-0002-1892-7985

Josephine Borghi

London School of Hygiene \& Tropical Medicine

\section{Research}

Keywords: Equity, inequality, direct costs, time costs, transport costs, universal coverage, healthcare financing, Tanzania

Posted Date: September 13th, 2021

DOI: https://doi.org/10.21203/rs.3.rs-864694/v1

License: (a) (i) This work is licensed under a Creative Commons Attribution 4.0 International License. Read Full License 


\section{Abstract}

Background: Direct and time costs of accessing and using health care may limit health care access, affect welfare loss, and lead to catastrophic spending especially among poorest households. To date, limited attention has been given to time and transport costs and how these costs are distributed across patients, facility and service types especially in poor settings. We aimed to fill this knowledge gap.

Methods: We used data from 1407 patients in 150 facilities in Tanzania. Data were collected in January 2012 through patient exit-interviews. All costs were disaggregated across patients, facility and service types. Data were analysed descriptively by using means, medians and equity measures like equity gap, ratio and concentration index.

Results: $71 \%$ of patients, especially the poorest and rural patients, accessed care on foot. The average travel time and cost were 30 minutes and 0.41 USD respectively. The average waiting time and consultation time were 47 minutes and 13 minutes respectively. The average medical cost was 0.23 USD but only $18 \%$ of patients paid for health care. The poorest and rural patients faced substantial time burden to access health care (travel and waiting) but incurred less transport and medical costs compared to their counterparts. The consultation time was almost similar across patients. Patients spent more time travelling to public facilities and dispensaries while incurring less transport cost than accessing other facility types, but waiting and consultation time was almost similar across facility types. Patients spent more time travelling to public facilities and dispensaries with less transport cost than accessing other facility types. Patients paid less amount in public than in private facilities. Postnatal care and vaccination clients spent less waiting and consultation time and paid less medical cost than antenatal care clients.

Conclusions: Our findings reinforce the need for a greater investment in primary health care to reduce access barriers and cost burdens especially among the worse-offs. Facility's construction and renovation and increased supply of healthcare workers and medical commodities are potential initiatives to consider. Other initiatives may need a multi-sectoral collaboration.

\section{Introduction}

Many developing countries are working to attain the universal health coverage (UHC) goal by 2030, which states that everyone needs to access good quality health care without incurring any financial hardship due to health care payment (WHO 2010). Underpinning UHC is equity in financing, accessing, and using health care services (Mills et al. 2012). Financing equity implies that payment for health care should be based on ability to pay, and equity in access implies that benefits from health care should be based on need regardless of their background characteristics (Kutzin 2013; Mills et al. 2012; Rodney \& Hill 2014). To date, the poorest in low-income countries are inadequately accessing and utilising quality health services, including maternal and child health (MCH) services (Barros et al. 2012; Victora et al. 2016). Financial cost is one of the barriers that prevent the poorest to access care (Ensor \& Cooper 2004; Mclntyre et al. 2009; O'Donnell 2007). They incur costs either directly by spending on transport and health care, or indirectly through income/ time loss for being unproductive (McIntyre et al. 2006). These costs are against the UHC Loading [MathJax]/jax/output/CommonHTML/jax.js 
goal as they pose financial risks and can push households into poverty (Mclntyre et al. 2006; WHO 2010; Xu et al. 2007).

The two measures of financial protection for UHC, catastrophic expenditure and impoverishment effect, only consider affordability in relation to direct medical costs (Wagstaff \& van Doorslaer 2003; WHO 2010). Most prepayment schemes focus on protecting people against the costs of health care, typically ignoring transport or travel costs (Chan 2016; WHO 2010). Analyses of health financing progressivity also focus on the distribution of direct medical payments and contributions to prepayment schemes across socioeconomic groups (Asante et al. 2016; Ataguba et al. 2018; O'Donnell et al. 2008). To date, other aspects of direct costs (e.g., transport costs) and indirect costs (e.g., time/ opportunity costs) have not been considered within equity analyses or in monitoring progress towards UHC.

However, evidence shows that time and transport costs can equally limit access to health care and sometimes even more than direct medical costs (Borghi et al. 2008; Ensor \& Cooper 2004; Mclntyre et al. 2009; O'Donnell 2007; Syed et al. 2013; Varela et al. 2019). For instance, patients may not seek care due to time costs to accessing care, due to distance or long waiting times at facilities (Macha et al. 2012; Mclntyre et al. 2009). Transport cost can also contribute to catastrophic expenditure (Xu et al. 2007), and sometimes representing a significant share of total out-of-pocket payments for health care (Barasa et al. 2017; Borghi et al. 2006; Masiye et al. 2016). When valued based on income foregone, time costs varied from $9-73 \%$ of total household cost of care seeking (Borghi et al. 2006; Sauerborn et al. 1995). Travel and time costs are significant for obstetric care, particularly when complications arise (Arsenault et al. 2013; Borghi et al. 2008; Mori et al. 2020; Powell-Jackson \& Hoque 2012). Kowalewski et al. (2002) revealed that transport costs were almost half of total expenditure for a normal delivery, while travel and waiting time were estimated at $65-93 \%$ of total household expenditure for a delivery. Given the potential significance of time and travel costs, it is equally important to assess their distribution across population subgroups to understand the equity implications of these costs in the premise of leaving no one behind towards UHC.

To date, the studies in Tanzania assessing the distribution of costs across population subgroups, have focused on direct medical expenditures (Castellani et al. 2015; Manzi et al. 2005; Mtei et al. 2012; Perkins et al. 2009) and catastrophic spending for health care (Brinda et al. 2014), only a few studies have examined the distribution of transport and time costs (Kowalewski et al. 2002; Neke et al. 2018; von Both et al. 2006). However, the studies on transport and time costs in Tanzania are either outdated and rural focused (e.g. (Kowalewski et al. 2002)), or had a narrow coverage of one district (e.g. (Neke et al. 2018; von Both et al. 2006)); but also did not compare different dimensions of time cost, and never examined the distribution of these costs across population subgroups, facility and service types.

This study, therefore, estimated time costs as well as transport and medical costs of accessing and utilising $\mathrm{MCH}$ services; explored the main driving cost items by comparing costs across facility types and $\mathrm{MCH}$ service types; and examined the distribution of costs across patient socioeconomic groups and place of residence (urban/rural) in Tanzania. This assessment provides evidence to policy makers by showing the areas that need health sector/ multisectoral interventions in order to improve access and use of primary and escential Mr.H servirec in Tanzania

Loading [MathJax]/jax/output/CommonHTML/jax.js

Page $3 / 27$ 


\section{Methods}

\subsection{Study setting}

Tanzania is a lower middle-income country in East Africa with an estimated population of around 56 million people in 2016 (NBS 2013). Tanzania has 31 regions and most (70\%) inhabitants are residing rural areas. Tanzania has made progress on child survival, with little improvement in maternal health as it stands at 556 deaths per 100000 live births (Afnan-Holmes et al. 2015; TDHS 2016). Access to one antenatal care (ANC) is almost universal, but there remains relatively low coverage of at least four ANC visits (51\%), institutional delivery (63\%) and postnatal care (PNC) (33\%) (TDHS 2016). The use of maternity services shows a marked imbalance along the continuum of care as reported elsewhere (Mohan et al. 2017; Owili et al. 2016; Singh et al. 2016). Also, 75\% of Tanzanian children age 12-23 months received all basic vaccinations (TDHS 2016).

The health system in Tanzania is largely dominated by public sector facilities, followed by faith-based providers, and limited numbers of private providers. The public health system has a hierarchical administrative structure, with a referral structure such that dispensaries, health centres, and district hospitals provide primary health care (PHC) services. A dispensary is supposed to serve at least one village, and a ward for a health centre (Maluka \& Chitama 2017). Tanzania implemented a Primary Health Service Development Programme (2007-2017) to improve access to basic health care service by rehabilitating and constructing at least one dispensary per village and a health centre per each ward countrywide (Maluka \& Chitama 2017).

The health financing system in Tanzania is highly fragmented with many sources to total health expenditure including general taxation (34\%), donor support (36\%), out-of-pocket payments (22\%), and health insurance contributions (8\%) (MOHCDGEC 2019b). In 2018, the health sector review revealed that $33 \%$ of Tanzanians are covered by health insurance, which include $8 \%$ by National Health Insurance Fund (NHIF) for public servants mainly, $25 \%$ by improved Community Health Fund (iCHF) for people working in informal sector, and $1 \%$ by private insurance and Social Health Insurance Benefit (SHIB) (MoHCDGEC 2019a). The coverage of health insurance is still low, which exposes many Tanzanians to financial risks due to direct health care payments. Despite exemption and waiver policies in Tanzania which aim to protect poor and vulnerable groups (e.g., pregnant women, children, and elders) (Maluka 2013; Mtei et al. 2014), the enforcement of these policies is weak (Kruk et al. 2008; Manzi et al. 2005). Also, the insurance schemes only cover medical expenses at facilities, but do not compensate patients for travel and time costs incurred when accessing care.

\subsection{Data}

Data were collected from a cross-sectional survey of patients from three regions (Pwani, Morogoro and Lindi) in Tanzania. All seven districts of Pwani region and four districts from Morogoro and Lindi region were included. This study was part of the large baseline survey of an impact evaluation of a pay for performance (P4P) programme in Pwani region (Binyaruka et al. 2015; Borghi et al. 2013). The evaluation study used Morogoro and Lindi as comparison regions. We sampled 75 facilities from Pwani region and the 
$(n=53)$ in each arm. Comparison facilities had similar levels of outpatient care visits and staffing levels to intervention facilities. In total, 150 public and private health facilities (12 hospitals, 32 health centres and 106 dispensaries) were surveyed (82\% were public facilities). Data were collected through patient exitinterviews to a maximum sample of 10 clients/ patients per facility between January and February 2012. Clients were approached upon arrival at the facility, asked a series of screening questions to check their eligibility. Eligible respondents included those resided in that area for at least six months, aged at least 18 years, and seeking care for one of the following four services: (i) ANC, (ii) child vaccination for under 1 year, (iii) PNC follow-up for mothers/ babies 2 months after birth, and (iv) check-up for fever, cough and diarrhoea for women/ under 5 children. Thus, respondents included pregnant women, mothers or care givers who brought under 5 children to the facility. Prior to the interview, all eligible clients were asked for their consent to participate in the survey after exiting the consultation room. The exit-interview tool measured a range of quality-of-care indicators including patient satisfaction/ experience of care, and costs of accessing and utilising health services. The exit-interviews also captured information on household background characteristics (e.g., ownership of assets and housing characteristics) that were used to assess the household's socioeconomic status. All the interviews were conducted in Swahili language. A tool was pretested for consistency, relevance, and clarity before the actual survey.

\subsection{Outcome variables}

The outcome of interest includes time costs as well as transport and medical costs. Time costs were estimated in minutes associated with traveling to and waiting or receiving consultation at the facility. Transport and medical costs were measured in local currency, Tanzanian shilling (TZS), and then converted into US dollar (USD) using the approximate exchange rate during the survey in 2012 (1 USD equal 1600 TZS). All costs were estimated based on patient recall. Transport and time costs of travelling were measured for one-way journey to the health facility. We 'multiplied by two' for simplicity to account for a return trip, since patients on their return sometime pass via markets or to other social activities as previously reported in Tanzania (Neke et al. 2018). In order to avoid overestimation, the one-way journey is preferred. For robustness check, however, we presented the estimates for both one and two-way travel costs.

\subsection{Equity dimensions}

We examined the distribution of time and direct costs by two dimensions of equity - (i) place of residence (rural/urban) and (ii) household's socioeconomic status. The rural-urban dimension was considered to reflect the remoteness and how facilities are scattered, which has important implications for transport costs and travel time; while the socioeconomic status was included to measure the households' living standard as a proxy of ability to pay. Household socioeconomic status was assessed through a wealth index based on household characteristics and asset ownership derived using principal component analysis based on 42 items (Appendix Tables 1 \& 2) (Filmer \& Pritchett 2001; Vyas \& Kumaranayake 2006). Patients were ranked by wealth scores from poorest (low score) to least poor (high score), and classified into five equal-sized quintiles. 
Table 1

Type of service sought by clients

\begin{tabular}{|l|l|}
\hline MCH service types & $\mathbf{N}=1407$ \\
\hline Antenatal care (ANC) & $334(23.7 \%)$ \\
\hline Postnatal care (PNC) -mother/ baby under 2 months & $380(27.0 \%)$ \\
\hline Postnatal care (PNC) -check-up (self/ baby under 5 years) & $557(39.6 \%)$ \\
\hline Child vaccination for under 1-year children & $136(9.7 \%)$ \\
\hline $\begin{array}{l}\text { Notes: PNC for follow up mothers and under two months babies after delivery; Check-up for self/ under } \\
5 \text { child check-ups for fever, cough and diarrhoea. }\end{array}$ \\
\hline
\end{tabular}


Table 2

Descriptive statistics of facility and patients' characteristics $(n=1407)$

\begin{tabular}{|c|c|c|c|}
\hline Characteristics & Description & Mean [SD] & Mean in \% \\
\hline \multicolumn{4}{|c|}{ Panel A: Facility characteristics } \\
\hline Facility ownership & $=1$ for public owned & & 81.9 \\
\hline Facility level of care & $=1$ for dispensary & & 67.7 \\
\hline Staffing level & Number of staff & $17.2[32.5]$ & \\
\hline \multicolumn{4}{|c|}{ Panel B: Clients' individual and household characteristics } \\
\hline Age of woman & Maternal age $(15-49)$ years & $26.8[7.0]$ & \\
\hline Age of a child & Child age in months & $15.6[13.4]$ & \\
\hline Marital status & $=1$ for married woman & & 68.0 \\
\hline Education & $=1$ for primary education/above & & 72.4 \\
\hline Occupation & $=1$ for farming activities & & 59.7 \\
\hline Religion & $=1$ for Muslim woman & & 73.2 \\
\hline Household size & Number of household members & $5.9[3.0]$ & \\
\hline Health insurance status & $=1$ for any insurance at household & & 8.9 \\
\hline Place of residence & $=1$ for rural district resident & & 82.8 \\
\hline \multicolumn{4}{|l|}{ Household SES } \\
\hline SES - quintile 1 & $=1$ for poorest household & & 20.0 \\
\hline SES - quintile 2 & $=1$ for poor household & & 19.9 \\
\hline SES - quintile 3 & $=1$ for middle wealth household & & 20.0 \\
\hline SES - quintile 4 & $=1$ for less poor household & & 19.9 \\
\hline SES - quintile 5 & $=1$ for least poor household & & 19.9 \\
\hline
\end{tabular}

\subsection{Data analysis}

We first describe the mean and median costs by patient socioeconomic status and residence. The equity analyses proceeded by using three measures of inequality - an absolute measure (the gap) and two relative measures (the ratio and the concentration index) (O'Donnell et al. 2008; WHO 2013). The equity gap was measured as the difference in costs between patient subgroups, while the equity ratio was measured as the ratio of costs between patient subgroups. Specifically, both equity gap and equity ratio were calculated Loading [MathJax]/jax/output/CommonHTML/jax.js well as between rural and urban patients. When comparing the 
poorest and least poor patients, for example, a positive (negative) gap and a ratio greater (less) than one defines high-cost burdens among the poorest (least poor), respectively. A gap of zero or a ratio of one defines an equal distribution in costs. We also used t-tests to assess whether the gaps were significantly different from zero.

In addition, we computed the concentration index $(\mathrm{Cl})$ to quantify the degree of socioeconomic-related inequality in cost burdens of seeking and receiving health care. The $\mathrm{Cl}$ was computed on a ranking variable of household socioeconomic status as shown in Eq. (1) (Kakwani et al. 1997; O'Donnell et al. 2008).

$$
C I=\frac{2}{\mu} \operatorname{cov}\left(y_{i}, R_{i}\right),
$$

1

where $y_{i}$ is the cost variable of the $i^{\text {th }}$ patient; $R_{i}$ is the fractional rank of the $i^{\text {th }}$ patient (in terms of households' socioeconomic status, with lower fractions for poorest and larger fractions for richest); $\mu$ is the average cost and cov denotes the covariance. The $\mathrm{Cl}$ ranges between [-1 and +1$]$, whereby zero indicate equality between socioeconomic status subgroups, while negative and positive values indicate that poorest have high-cost burdens and low-cost burdens, respectively. We also tested whether the Cls were significantly different from zero.

As a robustness check, our analysis was also restricted to public facilities (82\%) as these facilities are supposed to offer free MCH services in Tanzania. All analyses were performed using STATA version 16.

\section{Results}

\subsection{Characteristics of respondents and facilities}

A total of 1407 patients from 150 health facilities participated in exit-interviews. Most patients who were interviewed were seeking care for children under five years (39.6\%), while childhood vaccination was sought by the least clients $(9.7 \%)$ (Table 1$)$.

Most facilities visited were public owned, dispensaries, and had a staffing level of 17 health workers on average (Table 2). Patients were mostly residing in rural districts. A majority of respondents were married, farmers, Muslim, and with at least primary education. Few respondents $(9 \%)$ were from a household with a health insurance (Table 2).

\subsection{Time costs by socioeconomic status and place of residence}

We found most patients (71\%) accessed care on foot. The use of car, motorcycle or bicycle to access care was pro-rich while travelling on foot was pro-poor (Table 3 ). Figure 1 shows the average time costs of 
accessing and using health care and its distribution, while Appendix Table 3 shows the associated median value.

Loading [MathJax]/jax/output/CommonHTML/jax.js 
Table 3

Direct and indirect costs of accessing and utilising health care by socioeconomic status quintiles and place of residence

\begin{tabular}{|c|c|c|c|c|c|c|c|}
\hline & \multirow[b]{2}{*}{$\mathrm{n}$} & \multirow[b]{2}{*}{ Mean } & \multicolumn{2}{|c|}{$\begin{array}{l}\text { Socioeconomic status } \\
\text { Equity measures }\end{array}$} & \multirow[b]{2}{*}{$\begin{array}{l}\text { Concentration } \\
\text { Index (Cl) }\end{array}$} & \multicolumn{2}{|c|}{$\begin{array}{l}\text { Place of } \\
\text { residence } \\
\text { Equity measures }\end{array}$} \\
\hline & & & $\begin{array}{l}\text { Gap } \\
\text { (Poorest - } \\
\text { least } \\
\text { poor) }\end{array}$ & $\begin{array}{l}\text { Ratio } \\
\text { (Poorest/ } \\
\text { least } \\
\text { poor) }\end{array}$ & & $\begin{array}{l}\text { Gap } \\
\text { (Rural } \\
- \\
\text { Urban) }\end{array}$ & $\begin{array}{l}\text { Ratio } \\
\text { (Rural/ } \\
\text { Urban) }\end{array}$ \\
\hline Mode of transport & 1407 & (1) & (2) & (3) & (4) & (5) & $(6)$ \\
\hline Foot (\%) & $\begin{array}{l}(n= \\
1000)\end{array}$ & 71.1 & $22.1^{\star \star \star}$ & 1.4 & $-0.069 * \star \star$ & 4.0 & 1.1 \\
\hline Car (\%) & $\begin{array}{l}(n= \\
119)\end{array}$ & 8.5 & $-7.5^{\star \star}$ & 0.4 & 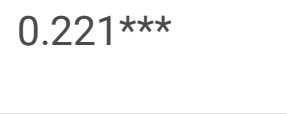 & -6.7 & 0.5 \\
\hline $\begin{array}{l}\text { Motorbike \& bicycle } \\
(\%)\end{array}$ & $\begin{array}{l}(\mathrm{n}= \\
288)\end{array}$ & 20.5 & $-14.7 * \star \star$ & 0.5 & $0.152^{\star \star \star}$ & 2.7 & 1.1 \\
\hline \multicolumn{8}{|l|}{ Time cost (mins) } \\
\hline Travel time for all & 1143 & 30.1 & $15.1^{\star \star \star}$ & 1.7 & $-0.109 \star \star \star$ & $5.5^{\star}$ & 1.2 \\
\hline Foot & $\begin{array}{l}(\mathrm{n}= \\
804)\end{array}$ & 31.3 & $14.7^{\star \star \star}$ & 1.6 & $-0.104^{\star \star \star}$ & 5.3 & 1.2 \\
\hline Car & $\begin{array}{l}(\mathrm{n}= \\
96)\end{array}$ & 26.7 & 1.1 & 1.0 & -0.019 & 0.3 & 1.0 \\
\hline Motorbike \& bicycle & $\begin{array}{l}(n= \\
243)\end{array}$ & 27.8 & $17.3^{\star \star}$ & 1.9 & $-0.141^{\star \star \star \star}$ & $8.4^{\star \star}$ & 1.4 \\
\hline Waiting time & 1394 & 46.7 & $15.3^{\star \star \star}$ & 1.4 & $-0.056^{\star \star}$ & $13.5^{\star \star}$ & 1.4 \\
\hline Consultation time & 1374 & 12.9 & -0.4 & 1.0 & 0.002 & 0.3 & 1.0 \\
\hline \multicolumn{8}{|l|}{ Direct cost (USD) } \\
\hline $\begin{array}{l}\text { Transport cost for } \\
\text { all clients }\end{array}$ & 1299 & 0.41 & $-0.51 \star \star \star$ & 0.2 & $0.269 * \star \star$ & $\overline{0.23 *}$ & 0.6 \\
\hline Car & $\begin{array}{l}(\mathrm{n}= \\
119)\end{array}$ & 1.32 & $-0.99 *$ & 0.5 & 0.184 & -0.87 & 0.6 \\
\hline Motorbike \& bicycle & $\begin{array}{l}(n= \\
267)\end{array}$ & 1.39 & $-0.75^{\star \star \star}$ & 0.4 & $0.065^{\star}$ & -0.31 & 0.8 \\
\hline
\end{tabular}

Notes: The median travel time overall $=20 \mathrm{~min}$, while on foot $(21.5 \mathrm{~min}), \mathrm{car}(20 \mathrm{~min})$ and other modes (20min); median travel cost = 0 USD; median waiting time $=26.5 \mathrm{~min}$, and consultation time $=10 \mathrm{~min}$; median medical cost $=0$ USD; travel time reflects a one-way journal; $* \star \star$ denotes significance at $1 \%$, $* \star$ at Loading [MathJax]/jax/output/CommonHTML/jax.js ince at 1\%, ** at 5\%, and * at $10 \%$ level 


\begin{tabular}{|c|c|c|c|c|c|c|c|}
\hline \multirow[b]{2}{*}{$\begin{array}{l}\text { Prob. of paying for } \\
\text { medical care }(\%)\end{array}$} & \multirow[b]{2}{*}{1399} & \multirow[b]{2}{*}{17.8} & \multicolumn{3}{|c|}{$\begin{array}{l}\text { Socioeconomic status } \\
\text { Equity measures }\end{array}$} & \multicolumn{2}{|c|}{$\begin{array}{l}\text { Place of } \\
\text { residence } \\
\text { Equity measures }\end{array}$} \\
\hline & & & $-9.3^{\star \star \star}$ & 0.6 & $0.128^{\star \star \star}$ & 1.4 & 1.1 \\
\hline $\begin{array}{l}\text { Medical cost for all } \\
\text { clients }\end{array}$ & 1399 & 0.23 & $-0.32^{\star \star \star}$ & 0.2 & $0.288 * \star \star$ & -0.16 & 0.6 \\
\hline
\end{tabular}

The average and median travel time to reach a facility were 30.1 minutes and 20 minutes, respectively. The burden of travel time was significantly dominated among the poorest and rural patients (Fig. 1). These patterns were supported by the positive equity gaps, negative concentration index, and equity ratios greater than one (Table 3). The average waiting time and consultation time were 46.7 minutes and 12.9 minutes, respectively (Fig. 1). Poorest and rural patients waited more than their counterparts, while consultation time was not significantly different across quintiles and place of residence (Table 3 ).

The total time cost of accessing and receiving health care were 90 minutes on average (120 minutes including return trip). This total time cost was driven by waiting time (52\%) followed by travel time (33.6\%) with relatively few minutes for consultation (Fig. 2). However, when considering total travel time including the return trip, the travel time takes the largest share of time costs (50.3\%) followed by waiting time (38.9\%) and consultation time.

\subsection{Direct costs by socioeconomic status and place of residence}

Figure 3 shows the direct transport and medical costs and their distributions, while Appendix Table 3 shows the associated median values. The average transport cost for one-way to reach a facility was 0.41 USD (the median value equals zero due to high degree of skewness, Appendix Table 3). The cost burden on transport was significantly higher among the least poor and urban patients than their counterparts (Fig. 3).

Consistently, the associated equity gaps were negative, with a positive concentration index and equity ratios less than one (Table 3).

In terms of medical cost, $17.8 \%$ of patients paid for health care at the point of use. On average, the medical cost incurred across all patients was around 0.23USD. However, the likelihood of paying and the average amount paid were greater among the least poor patients and urban residents than their counterparts (Fig. $3)$.

In terms of cost share, the transport cost took a larger share of direct cost. Specifically, transport costs to access care took almost two-thirds of direct cost (64.1\%) and more than three-quarter of total direct cost Loading [MathJax]/jax/output/CommonHTML/jax.js trip (Fig. 4). 
Table 4 shows the distribution of time and direct costs by facility ownership and level of care. Patients who accessed public facilities and dispensaries spent significantly more time travelling but incurred less transport cost than those who accessed non-public facilities and hospitals, respectively (Table 4). Waiting and consultation time was similar across facility types. As expected, due to free $\mathrm{MCH}$ services in public facilities, patients were significantly less likely to pay for care in public facilities but paid significantly more in non-public facilities (Table 4).

Table 4

Time and direct costs by facility ownership and level of care

\begin{tabular}{|c|c|c|c|c|c|c|c|c|}
\hline \multirow{2}{*}{$\begin{array}{l}\text { Cost } \\
\text { variable }\end{array}$} & \multirow[t]{2}{*}{$\mathbf{N}$} & \multirow[t]{2}{*}{ Mean } & \multicolumn{3}{|c|}{ Facility ownership } & \multicolumn{3}{|c|}{ Facility level of care } \\
\hline & & & $\begin{array}{l}\text { Public/ } \\
\text { government }\end{array}$ & FBO & $\begin{array}{l}\text { Private/ } \\
\text { other }\end{array}$ & Hospital & $\begin{array}{l}\text { Health } \\
\text { Centre }\end{array}$ & Dispensary \\
\hline & 1407 & (1) & (2) & (3) & (4) & (5) & (6) & (7) \\
\hline \multicolumn{9}{|l|}{$\begin{array}{l}\text { Time costs } \\
\text { (mins) }\end{array}$} \\
\hline $\begin{array}{l}\text { Travel time } \\
\text { for all } \\
\text { clients }\end{array}$ & 1143 & 30.1 & 31.6 (ref) & $25.5^{\star \star}$ & $22.3^{\star \star \star}$ & $\begin{array}{l}25.3 \\
\text { (ref) }\end{array}$ & 26.9 & $31.9 \star \star \star$ \\
\hline Waiting time & 1394 & 46.7 & 48.3 (ref) & $39.5^{\star}$ & 39.8 & $\begin{array}{l}59.3 \\
\text { (ref) }\end{array}$ & 45.9 & 45.1 \\
\hline $\begin{array}{l}\text { Consultation } \\
\text { time }\end{array}$ & 1374 & 12.9 & 12.9 (ref) & 12.8 & 13.4 & $\begin{array}{l}13.5 \\
\text { (ref) }\end{array}$ & 14.2 & 12.4 \\
\hline
\end{tabular}

\section{Direct cost \\ (USD)}

\begin{tabular}{lllllllll}
$\begin{array}{l}\text { Transport } \\
\text { costs for all } \\
\text { clients }\end{array}$ & 1299 & 0.41 & 0.32 (ref) & $0.76^{* \star *}$ & $0.95^{\star \star}$ & $\begin{array}{l}0.69 \\
\text { (ref) }\end{array}$ & 0.52 & $0.33^{\star \star *}$ \\
\hline Den
\end{tabular}

$\begin{array}{lllllllll}\begin{array}{l}\text { Prob. Of } \\ \text { paying for } \\ \text { care }(\%)\end{array} & 1399 & 17.8 & 13.0(\text { ref }) & 49.2^{\star \star *} & 17.1 & \begin{array}{l}19.3 \\ \text { (ref) }\end{array} & 8.9 & 20.5 \\ \end{array}$

$\begin{array}{lllllllll}\begin{array}{l}\text { Medical cost } \\ \text { for all }\end{array} & 1399 & 0.23 & 0.07 \text { (ref) } & 1.14^{\star \star \star} & 0.42 & \begin{array}{l}0.46 \\ \text { (ref) }\end{array} & 0.11^{\star} & 0.23\end{array}$

Notes: $* \star \star$ denotes significance at $1 \%, * \star$ at $5 \%$, and * at $10 \%$ level; t-test used public facility and hospital as reference groups; travel time reflects a one-way journal.

Table 5 shows the distribution of time and medical costs by types of $\mathrm{MCH}$ service sought. ANC patients spent significantly longer time waiting and in consultation with providers than those seeking other services (Table 5). The probability of paying for medical care did not vary by service types. However, PNC and vaccination clients paid less than ANC clients, and check-up clients paid more than ANC clients (Table 5). 
Table 5

Time and medical costs by service type sought

\begin{tabular}{|c|c|c|c|c|c|c|}
\hline \multirow[t]{2}{*}{ Cost variable } & \multirow{2}{*}{$\begin{array}{l}N= \\
1407\end{array}$} & \multirow[t]{2}{*}{ Mean } & \multicolumn{4}{|c|}{ Service type sought } \\
\hline & & & ANC & PNC & Vaccination & Check-up \\
\hline & $\begin{array}{l}(n= \\
334)\end{array}$ & $\begin{array}{l}(\mathrm{n}= \\
380)\end{array}$ & $(n=136)$ & $\begin{array}{l}(\mathrm{n}= \\
557)\end{array}$ & & \\
\hline \multicolumn{7}{|l|}{ Time cost (mins) } \\
\hline Waiting time (min) & 1394 & 46.7 & $\begin{array}{l}56.2 \\
\text { (ref) }\end{array}$ & $39.1^{\star \star \star}$ & $38.6^{\star \star}$ & 48.1 \\
\hline Consultation time (min) & 1374 & 12.9 & $\begin{array}{l}16.3 \\
\text { (ref) }\end{array}$ & $9.4^{\star \star \star}$ & $10.3^{\star \star \star}$ & $13.8^{\star \star \star}$ \\
\hline \multicolumn{7}{|l|}{ Medical cost (USD) } \\
\hline $\begin{array}{l}\text { Prob. Of paying for care } \\
(\%)\end{array}$ & 1399 & 17.8 & $\begin{array}{l}13.5 \\
\text { (ref) }\end{array}$ & 10.3 & 10.3 & 27.4 \\
\hline Medical cost for all clients & 1399 & 0.23 & $\begin{array}{l}0.17 \\
\text { (ref) }\end{array}$ & $0.06^{\star \star}$ & $0.04^{\star *}$ & $0.43^{\star * \star}$ \\
\hline
\end{tabular}

We further restricted the analysis to public facilities because of free $\mathrm{MCH}$ services in public facilities. This restriction increased slightly the average time costs (except consultation time) while average direct costs decreased (Appendix Table 4). The equity results remained almost unchanged between patients' subgroups.

\section{Discussion}

This study estimated time costs as well as transport and medical costs of accessing and utilising $\mathrm{MCH}$ services at PHC facilities, and examined the distribution of these costs across patient subgroups. This study adds to a limited evidence base examining transport and time costs and examining their equity in a LMIC setting. An advantage of the study is the use of patient exit-interviews to minimise recall bias. We found that overall, the time cost associated with seeking outpatient care was 90 minutes on average, driven primarily by travel and waiting time. The burden of travel and waiting time were significantly greater for the poorest groups, while consultation time was similar across wealth groups; waiting time was also significantly higher among rural compared to urban respondents. In terms of direct costs, transport costs were almost double compared to medical costs, with a large majority not facing medical costs associated with care seeking. The burden of transport and medical expenditures were significantly among the least poor and higher among urban respondents. Patients spent more time travelling to public facilities and dispensaries than other provider types, but waiting and consultation time did not vary significantly by facility types. Patients were less likely to pay for care in public facilities, and ANC clients faced the longest waiting and 
Our estimate of travel time, half an hour on average, is similar to a previous study in Tanzania (Kowalewski et al. 2002), but lower than a study in Malawi which estimated a median 1 hour travel time to a health centre (Varela et al. 2019). However, our estimate of 1.9 USD for transport cost among who paid something only (0.4 USD for all clients) is lower than previously reported 2.5 USD for only who paid something in Tanzania (Perkins et al. 2009). Our finding that the poorest and rural patients faced significant time burden accessing care and paid less amount on transport cost is largely explained by the means of transport, since the poorest and rural patients often travel on foot. In many settings including Tanzania, lower-level public facilities such dispensaries are much preferred by poorest and rural patients as closest facilities and they offer 'free' PHC services (Asante et al. 2016; Macha et al. 2012; Mtei et al. 2012).

Patients in our sample spent on average 47 minutes waiting for $\mathrm{MCH}$ services, 56 minutes for ANC only, which is less than previously reported (1 hour and half) for ANC in Tanzania (Neke et al. 2018). Our analysis revealed that the poorest and rural patients waited longer than their counterparts which is consistent with the pattern observed across hospitals in developed countries (Landi et al. 2018; Laudicella et al. 2012; Siciliani \& Verzulli 2009). Ours is the first study to reveal this evidence from a LMIC. However, the waiting time in developed countries is measured as number of days passed from the date a patient was added in the waiting list and the date of actual admission for treatment. In our setting, the longer waiting time to enter into the consultation room especially among the poorest and rural patients indicates the inadequate supply of health care -including shortage or maldistribution of health facilities and human resources for health (Macha et al. 2012). Tanzania like other developing countries has significant shortage of health staff with relatively more staff (e.g., specialists) in urban settings (Afnan-Holmes et al. 2015; Munga \& Maestad 2009). The better-offs also waited for shorter time possibly because they able to pay informal payment or 'under the table' to health workers in order to jump the queue (Maestad \& Mwisongo 2011).

Our study estimated about 16.3 minutes consultation time for ANC, which is slightly higher than 15 minutes reported earlier in southern Tanzania (von Both et al. 2006), higher than 10 minutes reported earlier in Dar es Salaam (Boller et al. 2003), but less than 20 and 48 minutes reported earlier in rural Ngorongoro district (Magoma et al. 2011) and in Kisarawe district for a mobile clinic (Neke et al. 2018), respectively. However, with the exception of consultation time reported by Neke et al. (2018), the other estimates falls below the recommended time between 30-40 minutes for ANC particularly first visit (WHO 2002). The consultation time in our study was generally similar across subgroups of patients. Our 13 minutes of consultation time for $\mathrm{MCH}$ services is relatively longer compared to approximately 5 minutes for outpatient consultation reported in Mozambique (Wagenaar et al. 2016) and Nigeria (Oche \& Adamu 2013). Since medical doctors and clinicians use longer consultation time than nurses and midwives (Boller et al. 2003), there is a need for qualified staff to offer comprehensive consultation to clients.

The finding that shows patients spent on average more time on waiting than consultation is consistent with findings from previous studies in Tanzania for ANC (Neke et al. 2018) and elsewhere for outpatient consultation (Oche \& Adamu 2013; Wagenaar et al. 2016). This is partly explained with the persistent shortage of healthcare workers and health facilities especially in poor countries (Darzi \& Evans 2016; Oche \& Adamu 2013; WHO 2016). We further found that services with shorter consultation time (e.g., PNC and 
vaccination) also had shorter waiting time. This implies that consultation time plays a significant role in explaining how long patients would wait for health care.

The total time cost of accessing and using $\mathrm{MCH}$ was largely driven by waiting time as previously reported in Tanzania (Kowalewski et al. 2002; Neke et al. 2018). In our study, the waiting time contributed almost $52.1 \%$ of total time cost, and about $53 \%$ when ANC service only considered. This is similar to previous studies that found half of the total time cost were spent waiting for ANC services in Tanzania (Kowalewski et al. 2002; Neke et al. 2018). However, when including the time spent travelling back home, travel time became the main contributor of total time cost. In terms of share for total direct cost, the main driver was transport cost which contains $64 \%$ of total costs, although it was less than a dollar on average. This finding is consistent to what reported earlier in southern Tanzania, where travel costs to access maternity services represented almost a half of total direct costs (Kowalewski et al. 2002). A similar pattern was reported in Nepal by Borghi et al. (2006), where transport cost took more than $50 \%$ of the total costs for clients seeking delivery care. However, in Bangladesh (Nahar \& Costello 1998) and Nigeria (Dalaba et al. 2015) transport cost took relatively lesser share of about $20 \%$ and $32 \%$ of total costs for maternity services, respectively. Also, transport cost accounted for $42 \%$ of health expenditure in South Africa (Goudge et al. 2009). Our results imply that transport cost contribute significantly to total health care costs, and have the potential to deter individuals from accessing health care especially among the poorest and those residing in remote areas.

Moreover, we found almost $18 \%$ of women paid for $\mathrm{MCH}$ services in Tanzania. When restricting the analysis to public facilities ( $82 \%$ in our sample), about $13 \%$ paid for $\mathrm{MCH}$ services that are supposed to be offered free of charge in Tanzania. However, the likelihood of paying for $\mathrm{MCH}$ service was significantly low in public compared to private facilities. Since our sample included only patients at the facility level, it is likely that the extremely poorer never accessed health facility due to financial barrier, and possibly our results are reflecting the least poor and near poor patients only. Unsurprisingly, the direct payments for exempted $\mathrm{MCH}$ services have been reported before in Tanzania (Kruk et al. 2008; Maluka 2013; Manzi et al. 2005) and elsewhere (Dalaba et al. 2015; Goudge et al. 2009; Nahar \& Costello 1998; Storeng et al. 2008). Paying for services which are exempted indicates a limited financial protection and weak enforcement of the exemption policy in Tanzania (Kruk et al. 2008; Maluka 2013). The inadequate budget allocation to the health sector (Ameur et al. 2012; Kruk et al. 2008) affects the enforcement of the exemption policy. In LMICs, however, expanding the resource envelop for health is constrained with limited fiscal space (Meheus \& McIntyre 2017) and the larger share of people in the informal sector who hardly enrol into prepayment mechanisms (Adebayo et al. 2015; Dror et al. 2016).

Our findings have important policy implications. Prepayment mechanisms and user fee removal are important steps towards UHC (WHO 2010), but does not guarantee health care access due to other barriers such as transport and time costs which are often neglected (Ensor \& Cooper 2004; O'Donnell 2007). Our finding indicates that the poorest and rural patients faced a relatively greater cost burden in terms of time loss from productivity partly because they have limited ability to pay for transport and/or health care; while their counterparts incurred huge direct cost because they have the ability to pay for transport and/or health care. Since the worse-off patients spent more time travelling, mostly on foot, to access public and lower Loading [MathJax]/jax/output/CommonHTML/jax.js greater investment in PHC facilities in order to bring quality 
health services closer to population as one of the recommended routes toward UHC (WHO 2019). This can be through PHC facility's construction and renovation and an increase in supply of healthcare workers and medical commodities. These initiatives may help to reduce the time and direct costs of accessing and using $\mathrm{PHC}$ especially in remote and rural areas. Investing in PHC facilities will also meet patients' needs and expectations and eventually reduce the time and travel cost incurred by patients bypassing closer PHC (Kahabuka et al. 2011; Kruk et al. 2009). In support of that argument, Tanzania implemented a Primary Health Care Services Development Programme (PHSDP) from 2007-2017 which involved construction and renovation of PHC facilities (Kapologwe et al. 2020; Maluka \& Chitama 2017); and interestingly, the current government is continuing with construction and renovation of PHC facilities. Investing in PHC facilities aligns with the Alma Ata Declaration on PHC in 1978 (WHO 1978) and the Astana Declarations of 2018 (Walraven 2019) for the purpose of achieving health for all and the UHC goal (WHO 2019). Future research in Tanzania should examine the effect of investing in PHC on time and direct costs of access and using health care.

Our findings highlight the need for policy makers to think on how the benefit packages of health insurance schemes can cover transport costs, and move away from covering medical costs only. Other approach to reduce the travel time especially among the worse-offs is improving access to means of transportation though would not necessarily affect the transport costs (Karra et al. 2016). The success of this approach depends on other sectors beyond the health sector (e.g., transportation and infrastructure sector), which indicates the need of multisectoral approach to reduce access/ geographical barriers. Further evidence suggest some potential initiatives to reduce the costs of accessing care such as conditional cash transfers (Lagarde et al. 2009), vouchers to cover transport costs (Schmidt et al. 2010; Van de Poel et al. 2014), expanding outreach services (e.g. mobile clinics)(Ensor \& Cooper 2004), establishing maternity waiting homes (Penn-Kekana et al. 2017) and implementing targeted policies for vulnerable and remote populations (Annear et al. 2019; Axelson et al. 2009). However, some of the suggested strategies are costly and may need a multisectoral collaboration.

This study has some strengths. First, we studied time costs of accessing and using $\mathrm{MCH}$ services as one of the cost aspects that received less attention despite its potential to limit health care access and use. Second, our time cost reflected a wider spectrum including time travelling, as well as waiting and consultation time. Third, this study examined the distribution of time and direct costs with equity implications. This is an important assessment as it shows who bears the cost burdens as an entry point for intervention. Fourth, we explored how time and direct cost varied by facility and service types, since previous studies largely focused on either one facility or service type. Lastly, we collected data through patient exitinterviews as an approach to reduce the recall bias as they had a recall period of less than 24 hours.

However, our study had some limitations. First, we did not assess the affordability of the amount paid due to unavailable data on household income/ expenditure to reflect the ability to pay. Second, we were unable to explore different coping strategies to finance costs of access and use due to data limitation. Third, we were unable to value the time costs (minutes) into monetary values because of unreliable income or wage rate data for rural and urban population. There is also considerable variation in measuring and valuing time Loading [MathJax]/jax/output/CommonHTML/jax.js es by age, gender, location or economic activity (Chima et al. 
2003; Mclntyre et al. 2006). Our sample also combined different service types which limits the process of valuing time lost. Fourth, although exit-interviews may have reduced recall bias, our findings reflect only those who were able to access and use health care. Lastly, we were unable to capture the hospitalisation costs for inpatient clients which adds significantly to cost burden, because of the survey design that focused on assessing quality of care for patients exiting after consultation.

\section{Conclusion}

This study highlights the importance of including time and transport costs alongside treatment costs when evaluating health care access and use, and financial protection towards UHC. It is critical as we found travel costs and waiting time as main drivers of total costs. Our findings also reinforce the need for policy makers to invest more on improving PHC facilities, as a way to reduce the time and cost burdens of accessing and using PHC services especially among the poorest and rural patients. This can be through facility's construction and renovation and increased supply of healthcare workers and medical commodities. However, efforts to reduce other access barriers may need a multisectoral collaboration.

\section{Abbreviations}

ANC: Antenatal Care

Cl: Concentration Index

DHS: Demographic Health Survey

ICHF: Improved Community Health Fund

LMICs: Low- and middle-income countries

$\mathrm{MCH}$ : Maternal and child health

MoHCDGEC: Ministry of Health, Community Development, Gender, Elderly and Children

NHIF: National Health Insurance Fund

P4P: Payment for performance

PHC: Primary Health Care

PHSDP: Primary Health Care Services Development Programme

PNC: Postnatal Care

SHIB: Social Health Insurance Benefit

TZS: Tanzanian Shilling 
UHC: Universal Health Coverage

USD: United states dollar

\section{Declarations}

\section{Ethical consideration}

Ethical approval for the evaluation study was obtained from the Institutional Review Board of the Ifakara Health Institute (approval number: 1BI1IRB/38) and the Ethics Review Board of the London School of Hygiene \& Tropical Medicine. Study participants provided written consent to participate in this study, requiring them to sign a written consent form that was read out to them by the interviewers. This consent form was reviewed and approved by the ethics committees prior to the start of the research.

\section{Consent for publication}

Not applicable

\section{Data Availability Statement:}

The data have been uploaded into a data repository. The DOI URL for the dataset is: 10.5281/zenodo.21709.

\section{Competing interests:}

The authors of this manuscript have the following competing interests: the two authors (PB and JB) were funded by the Government of Norway to undertake the data collection associated with this research. The Government of Norway also funded the P4P programme in Pwani region of Tanzania. The funder of the study had no role in data analysis, data interpretation, or writing of the manuscript.

\section{Funding}

The Government of Norway funded the data collection for the program evaluation that was used in this paper (grant numbers: TAN-3108 and TAN 13/0005. http://www.norad.no/en/). The funding body had no role in study design, data collection and analysis, decision to publish, or preparation of the manuscript. All authors had no funding for data analysis and writing of this paper.

\section{Author Contributions}


PB conceptualized this sub-study and oversaw data collection. PB analyzed the data and wrote the first draft of the manuscript. JB together with $\mathrm{PB}$ involved in data interpretation, presentation, and revision of the manuscript. All authors read and approved the final manuscript.

\section{Acknowledgements}

We would like to thank all healthcare providers, health managers and all health stakeholders who participated or facilitated to ensure a successfully fieldwork for data collection. We also thank the whole P4P evaluation research team, including data collectors and field coordinators. We also acknowledge the support from all field respondents, and various officials such as Regional Medical Officers, District Medical officers, Health facility in-charges, and P4P implementing agency.

\section{References}

1. Adebayo EF, Uthman OA, Wiysonge CS, et al. 2015. A systematic review of factors that affect uptake of community-based health insurance in low-income and middle-income countries. BMC Health Serv Res, 15: 543.

2. Afnan-Holmes H, Magoma M, John T, et al. 2015. Tanzania's countdown to 2015: an analysis of two decades of progress and gaps for reproductive, maternal, newborn, and child health, to inform priorities for post-2015. Lancet Glob Health, 3: e396-409.

3. Ameur AB, Ridde V, Bado AR, Ingabire M-G, Queuille L. 2012. User fee exemptions and excessive household spending for normal delivery in Burkina Faso: the need for careful implementation. BMC health services research, 12: 412.

4. Annear PL, Tayu Lee J, Khim K, et al. 2019. Protecting the poor? Impact of the national health equity fund on utilization of government health services in Cambodia, 2006-2013. BMJ Global Health, 4: e001679.

5. Arsenault C, Fournier P, Philibert A, et al. 2013. Emergency obstetric care in Mali: catastrophic spending and its impoverishing effects on households. Bull World Health Organ, 91: 207-16.

6. Asante A, Price J, Hayen A, Jan S, Wiseman V. 2016. Equity in Health Care Financing in Low- and Middle-Income Countries: A Systematic Review of Evidence from Studies Using Benefit and Financing Incidence Analyses. PLoS One, 11: e0152866.

7. Ataguba JE, Asante AD, Limwattananon S, Wiseman V. 2018. How to do (or not to do) ... a health financing incidence analysis. Health Policy Plan, 33: 436-444.

8. Axelson H, Bales S, Minh PD, Ekman B, Gerdtham U-G. 2009. Health financing for the poor produces promising short-term effects on utilization and out-of-pocket expenditure: evidence from Vietnam. International Journal for Equity in Health, 8: 20.

9. Barasa EW, Maina T, Ravishankar N. 2017. Assessing the impoverishing effects, and factors associated with the incidence of catastrophic health care payments in Kenya. Int J Equity Health, 16: 31. 
10. Barros AJ, Ronsmans C, Axelson H, et al. 2012. Equity in maternal, newborn, and child health interventions in Countdown to 2015: a retrospective review of survey data from 54 countries. Lancet, 379: 1225-33.

11. Binyaruka P, Patouillard E, Powell-Jackson T, et al. 2015. Effect of Paying for Performance on Utilisation, Quality, and User Costs of Health Services in Tanzania: A Controlled Before and After Study. PLoS One, 10: e0135013.

12. Boller C, Wyss K, Mtasiwa D, Tanner M. 2003. Quality and comparison of antenatal care in public and private providers in the United Republic of Tanzania. Bull World Health Organ, 81: 116-22.

13. Borghi J, Ensor T, Neupane BD, Tiwari S. 2006. Financial implications of skilled attendance at delivery in Nepal. Trop Med Int Health, 11: 228-37.

14. Borghi J, Mayumana I, Mashasi I, et al. 2013. Protocol for the evaluation of a pay for performance programme in Pwani region in Tanzania: a controlled before and after study. Implement Sci, 8: 80.

15. Borghi J, Storeng KT, Filippi V. 2008. Overview of the costs of obstetric care and the economic and social consequences for households. Reducing financial barriers to obstetric care in low-income countries.

16. Brinda EM, Andres AR, Enemark U. 2014. Correlates of out-of-pocket and catastrophic health expenditures in Tanzania: results from a national household survey. BMC Int Health Hum Rights, 14: 5.

17. Castellani J, Mihaylova B, Evers SM, et al. 2015. Out-of-pocket costs and other determinants of access to healthcare for children with febrile illnesses: a case-control study in rural Tanzania. PLoS One, 10: e0122386.

18. Chan M. 2016. Making Fair Choices on the Path to Universal Health Coverage. Health Syst Reform, 2: 57.

19. Chima RI, Goodman CA, Mills A. 2003. The economic impact of malaria in Africa: a critical review of the evidence. Health Policy, 63: 17-36.

20. Dalaba MA, Akweongo P, Aborigo RA, et al. 2015. Cost to households in treating maternal complications in northern Ghana: a cross sectional study. BMC health services research, 15: 34.

21. Darzi A, Evans T. 2016. The global shortage of health workers-an opportunity to transform care. Lancet, 388: 2576-2577.

22. Dror DM, Hossain SA, Majumdar A, et al. 2016. What Factors Affect Voluntary Uptake of CommunityBased Health Insurance Schemes in Low- and Middle-Income Countries? A Systematic Review and Meta-Analysis. PLoS One, 11: e0160479.

23. Ensor T, Cooper S. 2004. Overcoming barriers to health service access: influencing the demand side. Health Policy Plan, 19: 69-79.

24. Filmer D, Pritchett LH. 2001. Estimating wealth effects without expenditure data-or tears: an application to educational enrollments in states of India. Demography, 38: 115-32.

25. Goudge J, Gilson L, Russell S, Gumede T, Mills A. 2009. The household costs of health care in rural South Africa with free public primary care and hospital exemptions for the poor. Tropical medicine \& international health, 14: 458-467.

Loading [MathJax]/jax/output/CommonHTML/jax.js 
26. Kahabuka C, Kvale G, Moland KM, Hinderaker SG. 2011. Why caretakers bypass Primary Health Care facilities for child care - a case from rural Tanzania. BMC Health Serv Res, 11: 315.

27. Kakwani N, Wagstaff A, Van Doorslaer E. 1997. Socioeconomic inequalities in health: measurement, computation, and statistical inference. Journal of econometrics, 77: 87-103.

28. Kapologwe NA, Meara JG, Kengia JT, et al. 2020. Development and upgrading of public primary healthcare facilities with essential surgical services infrastructure: a strategy towards achieving universal health coverage in Tanzania. BMC Health Serv Res, 20: 218.

29. Karra M, Fink G, Canning D. 2016. Facility distance and child mortality: a multi-country study of health facility access, service utilization, and child health outcomes. International Journal of Epidemiology, 46 : 817-826.

30. Kowalewski M, Mujinja P, Jahn A. 2002. Can mothers afford maternal health care costs? User costs of maternity services in rural Tanzania. African journal of reproductive health: 65-73.

31. Kruk ME, Mbaruku G, McCord CW, et al. 2009. Bypassing primary care facilities for childbirth: a population-based study in rural Tanzania. Health Policy Plan, 24: 279-88.

32. Kruk ME, Mbaruku G, Rockers PC, Galea S. 2008. User fee exemptions are not enough: out-of-pocket payments for 'free' delivery services in rural Tanzania. Trop Med Int Health, 13: 1442-51.

33. Kutzin J. 2013. Health financing for universal coverage and health system performance: concepts and implications for policy. Bull World Health Organ, 91: 602-11.

34. Lagarde M, Haines A, Palmer N. 2009. The impact of conditional cash transfers on health outcomes and use of health services in low and middle income countries. Cochrane Database Syst Rev. Cd008137.

35. Landi S, Ivaldi E, Testi A. 2018. Socioeconomic status and waiting times for health services: An international literature review and evidence from the Italian National Health System. Health Policy, 122. 334-351.

36. Laudicella M, Siciliani L, Cookson R. 2012. Waiting times and socioeconomic status: evidence from England. Soc Sci Med, 74: 1331-41.

37. Macha J, Harris B, Garshong B, et al. 2012. Factors influencing the burden of health care financing and the distribution of health care benefits in Ghana, Tanzania and South Africa. Health Policy Plan, 27 Suppl 1: i46-54.

38. Maestad O, Mwisongo A. 2011. Informal payments and the quality of health care: Mechanisms revealed by Tanzanian health workers. Health Policy, 99: 107-15.

39. Magoma M, Requejo J, Merialdi M, et al. 2011. How much time is available for antenatal care consultations? Assessment of the quality of care in rural Tanzania. BMC Pregnancy Childbirth, 11: 64.

40. Maluka S, Chitama D. 2017. Primary health care systems (PRIMASYS): comprehensive case study from United Republic of Tanzania. World Health Organization (WHO).

41. Maluka SO. 2013. Why are pro-poor exemption policies in Tanzania better implemented in some districts than in others? Int $J$ Equity Health, 12: 80. 
42. Manzi F, Schellenberg JA, Adam T, et al. 2005. Out-of-pocket payments for under-five health care in rural southern Tanzania. Health Policy Plan, 20 Suppl 1: i85-i93.

43. Masiye F, Kaonga O, Kirigia JM. 2016. Does User Fee Removal Policy Provide Financial Protection from Catastrophic Health Care Payments? Evidence from Zambia. PLoS One, 11: e0146508.

44. Mclntyre D, Thiede M, Birch S. 2009. Access as a policy-relevant concept in low- and middle-income countries. Health Econ Policy Law, 4: 179-93.

45. Mclntyre D, Thiede M, Dahlgren G, Whitehead M. 2006. What are the economic consequences for households of illness and of paying for health care in low- and middle-income country contexts? Soc Sci Med, 62: 858-65.

46. Meheus F, Mclntyre D. 2017. Fiscal space for domestic funding of health and other social services. Health Econ Policy Law, 12: 159-177.

47. Mills A, Ataguba JE, Akazili J, et al. 2012. Equity in financing and use of health care in Ghana, South Africa, and Tanzania: implications for paths to universal coverage. Lancet, 380: 126-33.

48. Mohan D, LeFevre AE, George A, et al. 2017. Analysis of dropout across the continuum of maternal health care in Tanzania: findings from a cross-sectional household survey. Health Policy Plan.

49. MoHCDGEC. 2019a. Mid Term Review of the Health Sector Strategic Plan (HSSP) IV 2015-2020, Main Report. Ministry of Health Community Development, Gender, Elderly and Children (MoHCDGEC), Tanzania.

50. MOHCDGEC. 2019b. National Health Accounts (NHA) for financial years 2013/14, 2014/15 and 2015/16. Ministry of Health Community Development, Gender, Elderly and Children (MoHCDGEC), Tanzania.

51. Mori AT, Binyaruka P, Hangoma P, Robberstad B, Sandoy I. 2020. Patient and health system costs of managing pregnancy and birth-related complications in sub-Saharan Africa: a systematic review. Health Econ Rev, 10: 26.

52. Mtei G, Makawia S, Ally M, et al. 2012. Who pays and who benefits from health care? An assessment of equity in health care financing and benefit distribution in Tanzania. Health Policy Plan, 27 Suppl 1: i2334.

53. Mtei G, Makawia S, Masanja H. 2014. Monitoring and evaluating progress towards Universal Health Coverage in Tanzania. PLoS Med, 11: e1001698.

54. Munga MA, Maestad O. 2009. Measuring inequalities in the distribution of health workers: the case of Tanzania. Hum Resour Health, 7: 4.

55. Nahar S, Costello A. 1998. The hidden cost of 'free' maternity care in Dhaka, Bangladesh. Health Policy Plan, 13: 417-22.

56. NBS. 2013. Tanzania Population and Housing Census: Population Distribution by Administrative Areas 2012. National Bureau of Statistics (NBS): Dar es Salaam.

57. Neke N, Reifferscheid A, Buchberger B, Wasem J. 2018. Time and cost associated with utilization of services at mobile health clinics among pregnant women. BMC Health Serv Res, 18: 920. 
58. O'Donnell O. 2007. Access to health care in developing countries: breaking down demand side barriers. Cad Saude Publica, 23: 2820-34.

59. O'Donnell O, Van Doorsslaer E, Wagstaff A, Lindelöw M. 2008. Analyzing Health Equity Using Household Survey Data: A Guide to Techniques and Their Implementation. World Bank Publications.

60. Oche M, Adamu H. 2013. Determinants of patient waiting time in the general outpatient department of a tertiary health institution in north Western Nigeria. Annals of medical and health sciences research, $\mathbf{3}$ : 588-592.

61. Owili PO, Muga MA, Chou YJ, et al. 2016. Associations in the continuum of care for maternal, newborn and child health: a population-based study of 12 sub-Saharan Africa countries. BMC Public Health, 16: 414.

62. Penn-Kekana L, Pereira S, Hussein J, et al. 2017. Understanding the implementation of maternity waiting homes in low- and middle-income countries: a qualitative thematic synthesis. BMC Pregnancy and Childbirth, 17: 269.

63. Perkins M, Brazier E, Themmen E, et al. 2009. Out-of-pocket costs for facility-based maternity care in three African countries. Health Policy Plan, 24: 289-300.

64. Powell-Jackson T, Hoque ME. 2012. Economic consequences of maternal illness in rural Bangladesh. Health Econ, 21: 796-810.

65. Rodney AM, Hill PS. 2014. Achieving equity within universal health coverage: a narrative review of progress and resources for measuring success. Int J Equity Health, 13: 72.

66. Sauerborn R, Ibrango I, Nougtara A, et al. 1995. The economic costs of illness for rural households in Burkina Faso. Trop Med Parasitol, 46: 54-60.

67. Schmidt JO, Ensor T, Hossain A, Khan S. 2010. Vouchers as demand side financing instruments for health care: a review of the Bangladesh maternal voucher scheme. Health Policy, 96: 98-107.

68. Siciliani L, Verzulli R. 2009. Waiting times and socioeconomic status among elderly Europeans: evidence from SHARE. Health Econ, 18: 1295-306.

69. Singh K, Story WT, Moran AC. 2016. Assessing the Continuum of Care Pathway for Maternal Health in South Asia and Sub-Saharan Africa. Matern Child Health J, 20: 281-9.

70. Storeng KT, Baggaley RF, Ganaba R, et al. 2008. Paying the price: the cost and consequences of emergency obstetric care in Burkina Faso. Soc Sci Med, 66: 545-57.

71. Syed ST, Gerber BS, Sharp LK. 2013. Traveling towards disease: transportation barriers to health care access. Journal of community health, 38: 976-993.

72. TDHS. 2016. Tanzania Demographic and Health Survey and Malaria Indicator Survey 2015-16. National Bureau of Statistics (NBS): Dar es Salaam.

73. Van de Poel E, Flores G, Ir P, O'Donnell O, Van Doorslaer E. 2014. Can vouchers deliver? An evaluation of subsidies for maternal health care in Cambodia. Bull World Health Organ, 92: 331-9.

74. Varela C, Young S, Mkandawire N, et al. 2019. Transportation barriers to access health care for surgical conditions in Malawi a cross sectional nationwide household survey. BMC public health, 19: 264. 
75. Victora CG, Requejo JH, Barros AJ, et al. 2016. Countdown to 2015: a decade of tracking progress for maternal, newborn, and child survival. Lancet, 387: 2049-59.

76. von Both C, Flessa S, Makuwani A, Mpembeni R, Jahn A. 2006. How much time do health services spend on antenatal care? Implications for the introduction of the focused antenatal care model in Tanzania. BMC Pregnancy Childbirth, 6: 22.

77. Vyas S, Kumaranayake L. 2006. Constructing socio-economic status indices: how to use principal components analysis. Health Policy Plan, 21: 459-68.

78. Wagenaar BH, Gimbel S, Hoek R, et al. 2016. Wait and consult times for primary healthcare services in central Mozambique: a time-motion study. Global health action, 9: 31980-31980.

79. Wagstaff A, van Doorslaer E. 2003. Catastrophe and impoverishment in paying for health care: with applications to Vietnam 1993-1998. Health Econ, 12: 921-34.

80. Walraven G. 2019. The 2018 Astana Declaration on Primary Health Care, is it useful? J Glob Health, 9: 010313.

81. WHO. 1978. Primary health care: report of the International Conference on primary health care, AlmaAta, USSR, 6-12 September 1978. World Health Organization, World Health Organization.

82. WHO. 2002. WHO antenatal care randomized trial: manual for the implementation of the new model. World Health Organization. 9241546298.

83. WHO. 2010. The World Health Report: Health Systems Financing: The path to universal coverage. In: Geneva (ed). World Health Organization, Geneva, Switzerland: World Health Organization.

84. WHO. 2013. Handbook on health inequality monitoring: with a special focus on low- and middle-income countries. World Health Organization, Geneva, Switzerland.

85. WHO. 2016. Draft global strategy on human resources for health- workforce 2030. World Health Organization.

86. WHO. 2019. Primary health care on the road to universal health coverage: 2019 monitoring report. World Health Organization (WHO).

87. Xu K, Evans DB, Carrin G, et al. 2007. Protecting households from catastrophic health spending. Health Aff (Millwood), 26: 972-83.

\section{Figures}




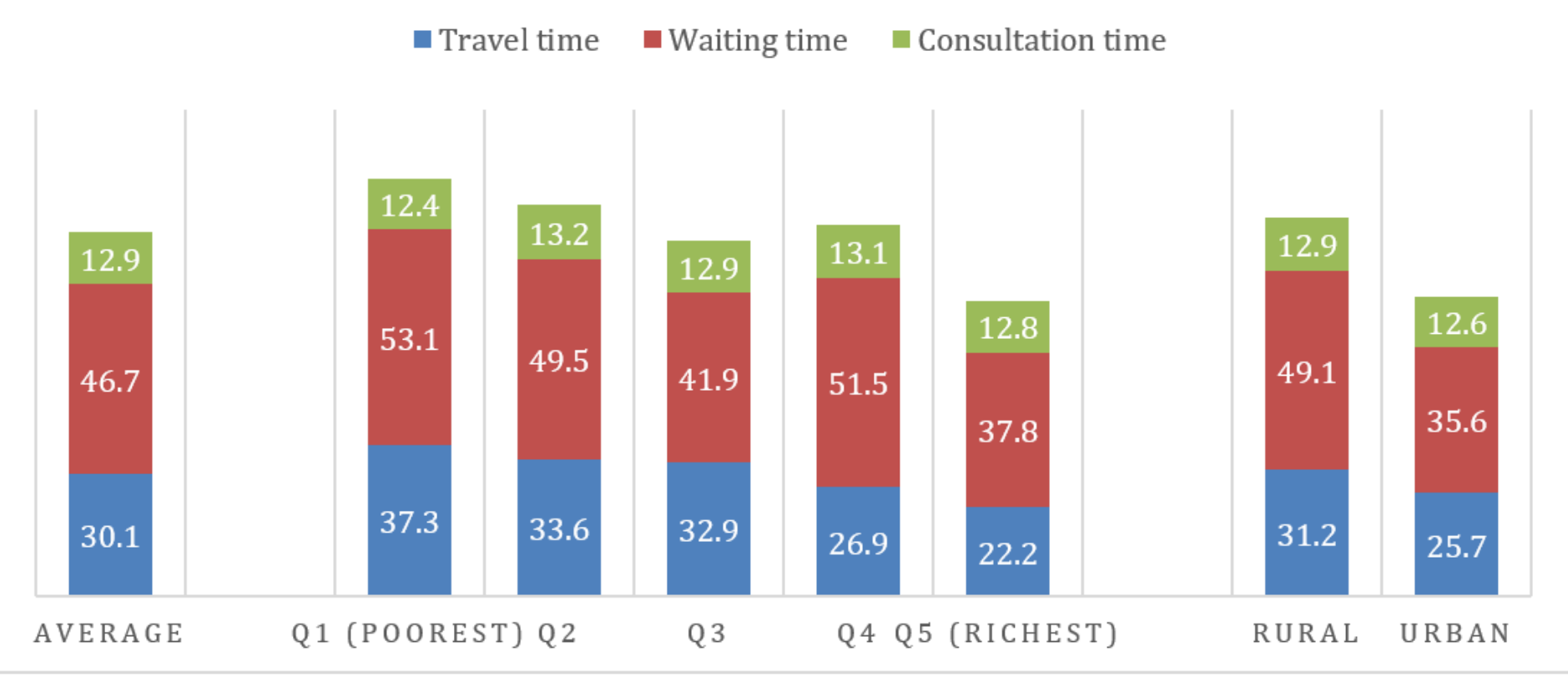

\section{Figure 1}

Time costs of accessing and utilising health services (in minutes)

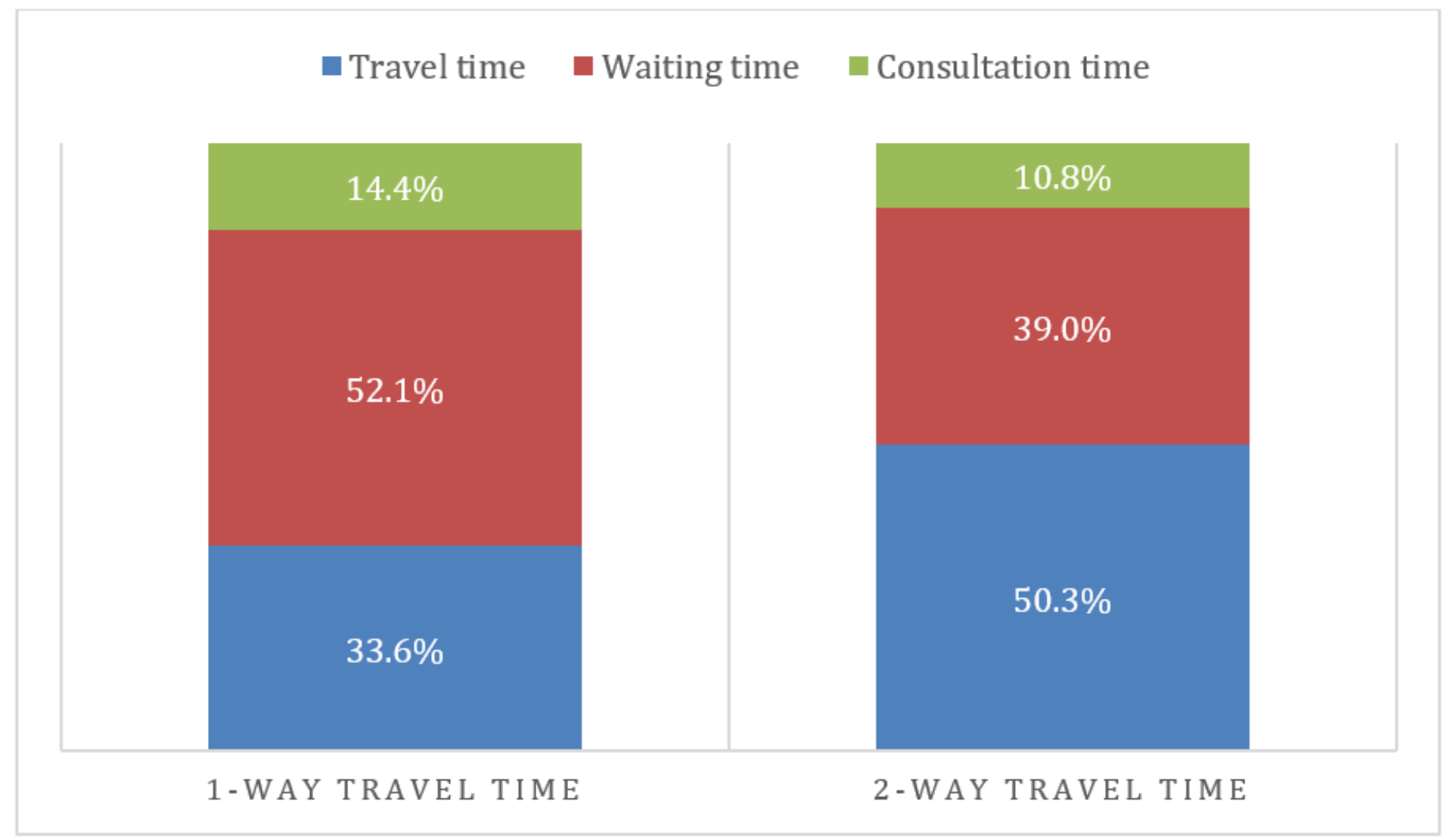

Figure 2

Share of overall time costs 


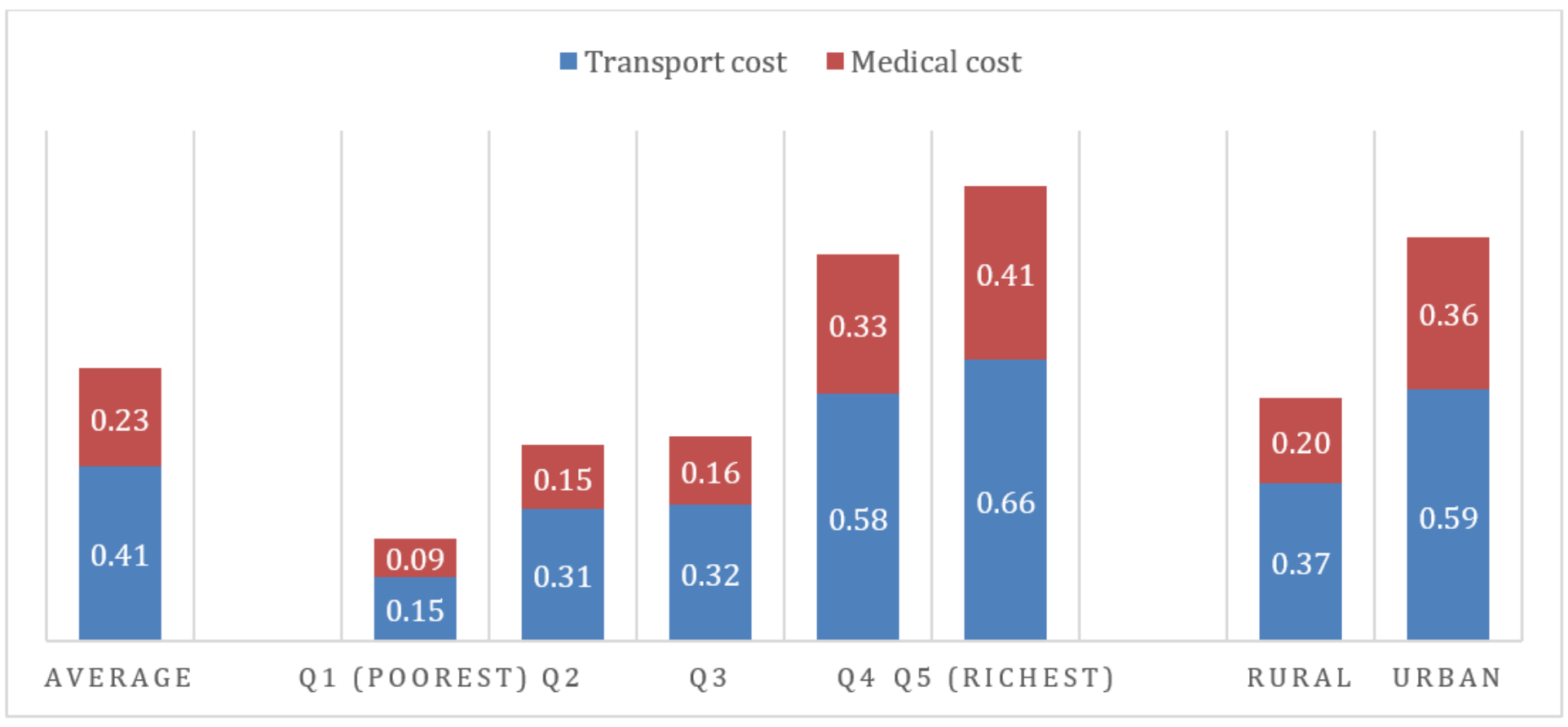

\section{Figure 3}

Direct costs of accessing and utilising health services (in USD)

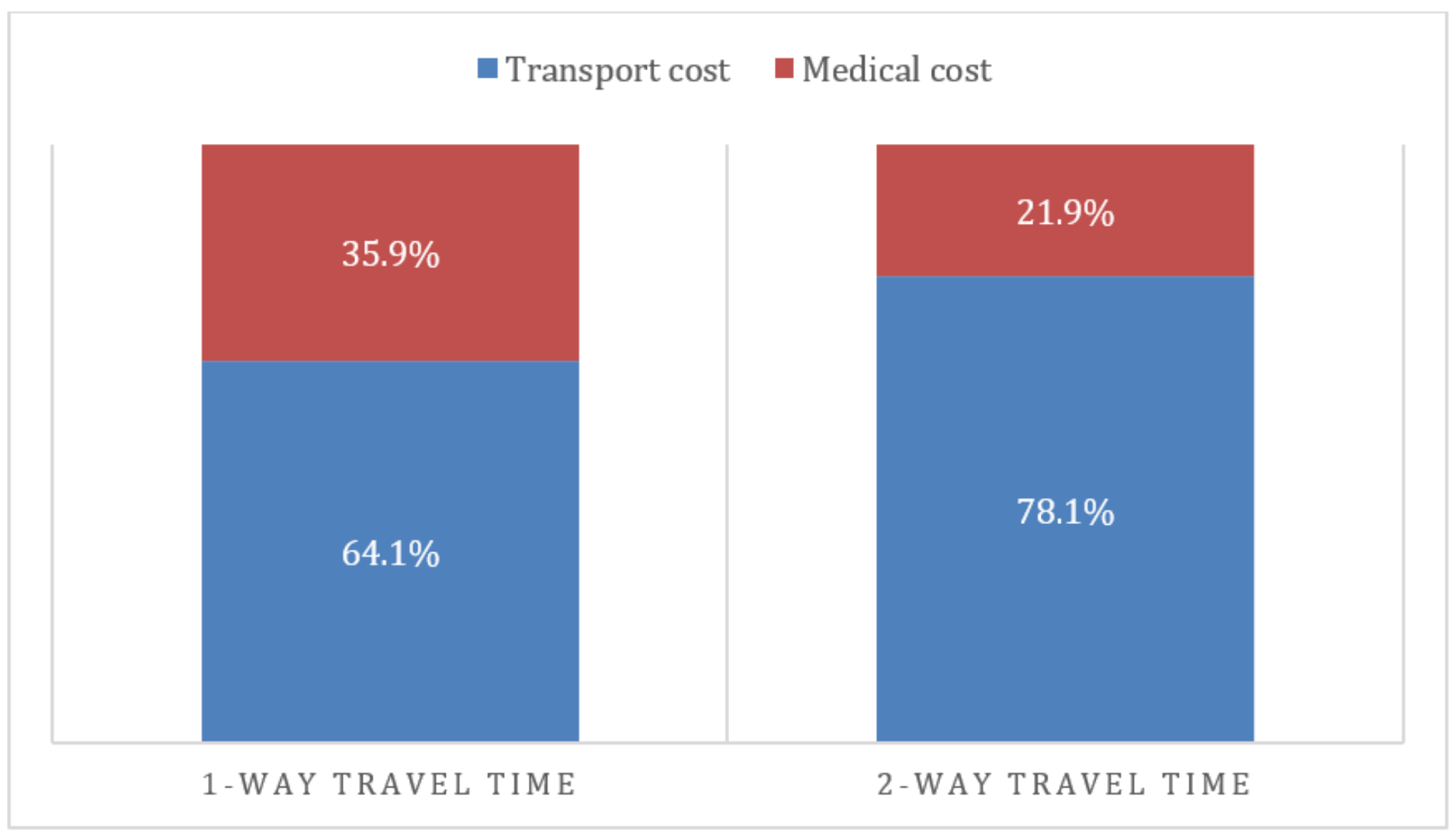

\section{Figure 4}




\section{Supplementary Files}

This is a list of supplementary files associated with this preprint. Click to download.

- AppendixTables.docx 